ARTIGO

Recebido em:

25/07/2012

Aceito em: 29/01/2013

\title{
0 exercício da arquitetura da informação na Web: reflexões relativas à Lei dos Direitos Autorais
}

\section{The practice of information architecture on the Web: thoughts related to the Copyright Law}

\author{
Rosilene Paiva Marinho de SOUSA ${ }^{1}$ \\ Guilherme Ataíde DIAS ${ }^{2}$ \\ Bernardina OLIVEIRA ${ }^{3}$ \\ Marckson SOUSA ${ }^{4}$
}

\section{RESUMO}

Apresenta uma reflexão sobre a Arquitetura da Informação (AI) e a Lei no 9.610, de 19 de fevereiro de 1998, que regula os Direitos Autorais, considerando-se o livre acesso à informação, sem esquecer as questões éticas e legais. A metodologia aplicada é de natureza qualitativa, bibliográfica e de caráter exploratório. São abordados os componentes da Arquitetura da Informação, além de tecer uma discussão sobre os direitos autorais pertinentes aos referidos componentes da AI existentes nos websites. 0 livre acesso à informação é um fator primordial, mas devem ser impostas exigências que regulamentem projetos derivados, atentando-se para as leis que regulamentam os direitos autorais e produtos de software, levando em consideração o conteúdo neles expostos, para possíveis modificações.

PALAVRAS-CHAVE: Arquitetura da Informação. Acesso à informação. Direitos autorais.

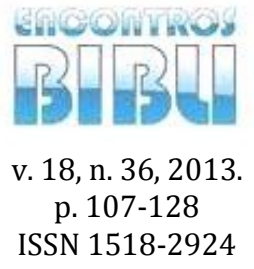

\begin{abstract}
1 Universidade Federal da Paraíba - adv.rpmarinho@gmail.com

2 Universidade Federal da Paraíba - guilhermeataide@gmail.com

3 Universidade Federal da Paraíba - bernardinafreire@gmail.com

${ }^{4}$ Universidade Federal da Paraíba - marckson.dci.ufpb@gmail.com
\end{abstract}

Presents a reflection on Information Architecture (IA) and Law No. 9.610 of February 19, 1998, which governs the Copyright, considering free access to information, without forgetting the ethical and legal issues. The applied methodology is qualitative through library research and

Esta obra está licenciada sob uma Licença Creative Commons 
exploratory. The IA components are addressed and a discussion of the relevant copyright components of the existing AI on websites are commented. Free access to information is a primary factor, but should be imposed requirements governing derivative projects, paying attention to the laws governing copyrights and software products, considering the content in them exposed to possible modifications.

KEYWORDS: Information Architecture. Information Access. Copyright.

\section{INTRODUÇÃo}

A tecnologia tem apresentado inúmeros avanços nos últimos anos nos mais diversos setores da atividade humana, destacam-se de forma precípua os progressos na área das Tecnologias Digitais da Informação e Comunicação (TDIC), que abrangem as tecnologias computacionais, as telecomunicações e têm na Internet a sua mais forte expressão, contribuindo para a ampliação do potencial humano na realização dos mais diversos tipos de atividades (SILVA, 2010).

Nesse contexto, a Internet apresenta uma rápida expansão, conduzindo a uma reflexão sobre seus impactos na sociedade, economia, política e cultura (CAPOBIANCO, 2010). Observa-se a ocorrência do desenvolvimento da informática e das telecomunicações, como instrumentos de suporte ao fenômeno conhecido como sociedade da informação. Castells (1999) esclarece que a sociedade da informação corresponde àquela que recebe os impactos informacionais. Porém, o referido autor prefere o termo "sociedade informacional", cujo termo indica o atributo de uma forma específica de organização social em que a geração, processamento e transmissão da informação são fontes fundamentais de produtividade e poder (CASTELLS, 1999).

A utilização da Internet tem possibilitado a interligação dos vários setores da economia e possibilitado a transformação de praticamente todas os segmentos da sociedade, o que vem a incrementar as oportunidades disponíveis para a disseminação de informações, sobretudo através da utilização de websites e redes sociais. Com a consolidação da sociedade da informação, e a quantidade crescente de conteúdo relevante disponível, a informação tem se 
destacado como um insumo gerador de riquezas e um dos principais bens disponíveis pelas organizações, contribuindo para o processo da tomada de decisões e a geração de conhecimentos.

As informações disponibilizadas nas páginas de um website podem crescer de forma significativa em um curto período de tempo, podendo ser acessadas por vários usuários simultaneamente, além da possibilidade de serem editadas de forma compartilhada. Porém neste cenário existe uma barreira referente à organização da informação que pode comprometer a sua efetiva recuperação pelos usuários. De acordo com Sousa et al. (2010), transformações podem acontecer nas páginas de um website com o objetivo de torná-las mais interativas e dinâmicas, mas que podem gerar desconforto aos usuários, resultando até mesmo em perdas significativas de informação e eventualmente gerando uma insatisfação quando do acesso a esses espaços informacionais. Ainda segundo os mesmos autores, as alterações devem acontecer de forma controlada, sem mudanças constantes na estrutura do website como forma de inovação, pois isso pode causar desorientação dos usuários. Ao se buscar uma informação cuja recuperação é insatisfatória, o usuário pode não ter acesso a aspectos relevantes ou pode até mesmo sair do website e não mais retornar causando consequentemente prejuízos para a instituição (SOUSA et al., 2010).

Instituições que objetivam se firmar no mercado virtual, buscam realizar projetos coerentes para o desenvolvimento de seus websites, seja internamente ou através da terceirização de serviços. Nesse sentido, é necessário o conhecimento de diversos profissionais que devem se unir para que seja possível o desenvolvimento coerente da arquitetura informacional das páginas e/ou sistemas de informação, considerando a sua participação e união, a exemplo de analistas de negócios, especialistas em interfaces com o usuário, projetistas gráficos, desenvolvedores de sistemas Web, programadores, arquitetos da informação e operadores do direito, sobretudo para que estes últimos possam assessorar os demais quanto aos seus direitos e deveres no que tange ao ambiente informacional (SCHEWICK, 2010). Essa cooperação deve existir principalmente devido à necessidade de responder a algumas questões, tais como: 0 que está sendo proposto reflete as necessidades da instituição? 0 
quanto importante é a conformidade aos princípios da Arquitetura da Informação (AI)? O conteúdo disponibilizado vai de encontro a alguma norma interna da instituição ou do país? Existe violação de direitos autorais quando da construção da AI do website? Respostas para estas questões podem ser bem mais complexas do que aparentam a um primeiro olhar.

Após vários anos de preocupação dos desenvolvedores quase que exclusivamente para com inovações tecnológicas, surge a necessidade de se ter conhecimento das leis e normas que regem as várias ações, sobretudo na Internet, e principalmente ao se considerar a amplitude do número de usuários. Dificuldade similar surge também quando se busca entender como a AI pode afetar o sucesso ou fracasso do investimento de instituições no mundo virtual. De forma equivalente a maneira como a arquitetura tradicional descreve as bases para a construção de uma casa, a AI para um produto informacional descreve a estrutura de seus componentes básicos e sua interligação, de forma que os mesmos possam interagir para alcançar a funcionalidade desejada e maximizar a experiência do usuário.

Conforme o pensamento de Bustamante (2004), a organização da informação é um dos fatores que influenciam diretamente para o sucesso ou fracasso dos websites das instituições, esta organização é o processo que prevê e organiza a sequência de elementos que compõem o conteúdo do website. Aspectos relativos à organização da informação podem ser encontrados na AI, que pode ser utilizada para organizar a informação, não apenas na $W e b$, mas em produtos de software mais genéricos, tais como aplicações voltadas para dispositivos móveis, de forma que os usuários tenham a possibilidade de recuperar informações relevantes, de forma cada vez de forma mais otimizada.

Um bom projeto de AI pode contribuir para facilitar à compreensão do conteúdo disponibilizado pelo produto de informação, além de ajudar o processo de tomada de decisão. Isso não é alcançado de forma trivial, pois é imprescindível considerar que os usuários têm diferentes necessidades, possuem diferentes ideias sobre o que desejam, além da percepção de que muitos sabem trabalhar com tecnologia, enquanto outros não possuem a menor 
ideia de como iniciar ou aproveitar os recursos disponibilizados pelos sistemas de informação automatizados.

Os desenvolvedores de aplicações Web desfrutam de uma grande liberdade no processo de desenvolvimento, mas na maioria das vezes não consideram as leis existentes no ordenamento jurídico. As organizações podem utilizar recursos financeiros e estratégias para a criação de uma AI para a Web estratégica objetivando alcançar sucesso no ambiente virtual, porém podem existir "cópias" dessa arquitetura por outras instituições, o que pode conduzir a processos judiciais, sobretudo no que se refere a causas relativas à violação de direitos autorais. Neste artigo é apresentada uma reflexão inicial sobre a AI na $W e b$ e os aspectos relativos aos direitos autorais, considerando-se o livre acesso à informação.

\section{A IMPORTÂNCIA DA ARQUITETURA DA INFORMAÇÃO}

A emergência da sociedade da informação acelerou um processo de mudanças sócio-culturais caracterizado, entre outros fatores, pela rápida disseminação da informação e facilidades de comunicação no cenário global, principalmente por meio das TDIC. Com o advento de ferramentas específicas, a disseminação e o acesso às informações de diferentes naturezas passam a ocorrer de forma ampla. Diferentes atores sociais ou instituições podem assumir, ainda que informalmente, a função de uma "unidade de informação" no ciberespaço e conseguir a atenção dos usuários ao longo do processo de busca por informações na $W e b$.

Ao se acessar a Internet, a ação de replicar conteúdos já publicados em outras instâncias da rede, dependendo da fonte associada à informação, pode representar uma prática não recomendada, pois, muitas frequentemente isto conduz a litígios judiciais, que podem inclusive culminar com a ordem para que o website seja retirado de funcionamento. Nesse contexto, impõe-se a exigência de normas, que regulamentem o acesso à informação decorrente das referidas transformações nas comunicações e nas relações humanas associadas a contemporaneidade. 


\subsection{Considerações relacionadas à arquitetura da informação em um}

\section{sistema de software}

0 acesso à informação registrada pode acontecer sobre praticamente todo e qualquer tipo de suporte existente. Ao se considerar as informações disponibilizadas no meio virtual é possível perceber as facilidades disponibilizadas através do uso da Internet, onde os usuários têm a possibilidade de obter informações sobre praticamente qualquer assunto, envolvendo eventos passados ou acontecimentos que ocorreram a poucos instantes. Essa mudança de paradigma em relação às informações disponibilizadas em meio analógico tem favorecido o trabalho da vasta maioria de usuários, mas também tem se demonstrado um desafio para a organização eficaz das informações, considerando-se principalmente a fidedignidade das mesmas e sua repetição desordenada, que podem gerar muitas vezes mais problemas que soluções.

A AI possibilita: organizar o conteúdo informacional; descrevê-lo de maneira clara; e proporcionar formas para que as pessoas recuperem a informação desejada de modo mais simples e efetivo possível.

A arquitetura de um software relaciona-se a disposição global dos elementos que o constituem e aos modos pelos quais essa estrutura fornece integridade conceitual para um sistema (PRESSMAN, 2006). 0 autor comenta de forma mais simples que a arquitetura é uma estrutura hierárquica dos componentes (módulos), o modo pelo qual esses componentes interagem e a estrutura de dados utilizada pelos mesmos. Um dos objetivos de um projeto de software é conceber um quadro arquitetural do sistema, que serve como arcabouço a partir do qual atividades de projeto detalhado são conduzidas.

Ao se analisar a arquitetura de um edifício, muitos componentes estruturais podem ser pensados de forma similar a um software, tais como módulos compartilhados, divisões hierárquicas, forma de interface humanocomputador, dentre outros. De forma mais simples, pode-se pensar apenas na estrutura física do edifício ressaltando-se que a arquitetura é bem mais que isso. Ela corresponde à maneira pela qual os vários componentes estão integrados 
para formar um todo, de forma semelhante como acontece com os componentes que envolvem a AI.

De acordo com Pressman (2006, p. 208), a arquitetura não corresponde ao software em funcionamento, mas é a representação que possibilita:

1. Analisar a efetividade do projeto em satisfazer seus requisitos declarados;

2. Considerar alternativas arquiteturais num estágio em que fazer modificações de projeto é ainda relativamente fácil e;

3. Reduzir os riscos associados com a construção do software.

Neste contexto, a arquitetura é de extrema importância, uma vez que se constitui em um modelo, mesmo que seja considerado de forma relativamente simples, mas que é intelectualmente inteligível de como o sistema é estruturado e como seus componentes trabalham em harmonia.

A AI para a Web fornece subsídios fundamentais para a organização de um website, contudo, não se deve esquecer que aspectos legais sobre os elementos dessa arquitetura devem ser considerados quando da disponibilização das informações, uma vez que existem leis que regulamentam os direitos autorais e que são deixadas de lado na maioria das vezes, principalmente por desconhecimento dos autores das obras, por questões não explicitas na lei ou através de riscos assumidos pelos responsáveis.

0 acesso livre ao conhecimento deve ser primordial, mas o respeito à produção intelectual não pode deixar de ser considerada. A forma como a informação atinge os mais variados públicos é uma característica marcante da sociedade da informação, sendo necessária uma adequação da forma de propagação das mesmas. A proteção à propriedade intelectual é uma maneira de garantir o ciclo de inovação científica e tecnológica, pois estimula o fomento de novas ideias mediante a justa recompensa dos detentores dos direitos pertinentes ao produto do intelecto. 


\subsection{Considerações específicas aos sistemas Web}

Nos projetos relacionados a construção de sistemas para a web, os responsáveis pelo processo de desenvolvimento devem conhecer o contexto em que seu cliente está inserido, propondo nos wireframes modelos que atinjam o objetivo do cliente e que vão ao encontro às boas práticas de acessibilidade e usabilidade.

De acordo com Oliveira (2003), o wireframe é um documento que se torna cada vez mais fundamental para o trabalho do arquiteto de informação. Os wireframes (estrutura equivalente a uma planta baixa) correspondem a um dos componentes estruturantes do processo de desenvolvimento dos websites, onde se realiza a definição de sua estrutura, normalmente organizando de forma hierárquica os elementos e informações que devem estar presentes em cada uma das páginas. Neste contexto, não deve esquecer-se de considerar a forma como o usuário interage na $W e b$ e com outros ambientes informacionais.

Durante esse processo, deve existir a indicação do grau de relevância de cada elemento e sua relação com os demais elementos formadores do contexto. Também é recomendado que exista a indicação correta dos textos, breadcrumbs $^{5}$ de navegação, guidelines ${ }^{6}$ e até dos recursos de programação e tecnologias a serem utilizados pela equipe de desenvolvimento (OLIVEIRA, 2003). Posteriormente, eles podem ser utilizados para marcação das etapas de um processo de interação entre usuário e sistema, servindo também como baliza para possíveis considerações de testes iniciais de usabilidade.

Durante o projeto de um website, existe uma definição inicial de suas características, sendo permitido, porém que adaptações sejam realizadas pelos usuários, dependendo do grau de flexibilidade pensado no planejamento. Segundo Morville (2005) a personalização do site pode possibilitar uma maior facilidade na recuperação da informação em virtude do sistema estar de acordo com as preferências do usuário, ou pelo menos de acordo com sua concepção sobre o tema abordado pela instituição. Nesse sentido, existem várias

\footnotetext{
${ }^{5}$ Modelo de navegação em que é apresentada uma linha no topo de cada página indicando a localização da referida página na hierarquia atual.

${ }^{6}$ Guias de estilo - documento que visa agilizar processos específicos de acordo com uma rotina definida.
} 
características que podem ser consideradas, porém a de maior relevância refere-se à encontrabilidade ${ }^{7}$ que precede até mesmo a usabilidade. Um usuário só pode tomar uma decisão correta se as alternativas que lhe forem oferecidas forem relevantes para atender suas necessidades. Informações ambíguas podem conduzir a um desinteresse, sem mesmo possibilitar uma escolha satisfatória (MORVILLE, 2005).

Num site de vendas, por exemplo, para cada etapa do processo de compra deve haver um wireframe que mapei todas as possibilidades de interação e o caminho percorrido pelo usuário, como uma sequencia de busca pelo produto, inserção na cesta de compras, identificação da forma de pagamento, confirmação das informações fornecidas. Na construção do mesmo, o arquiteto da informação deve buscar representar esquematicamente os elementos que compõem a página.

O wireframe apresenta diversas utilidades, tais como, facilitar a aplicação de conceitos de usabilidade já testados e comprovadamente eficientes; auxiliar a equipe de desenvolvimento e programação na tarefa de produzir o website de maneira mais rápida, padronizada e eficiente; funcionar como uma documentação do website e deve ser consultado antes de cada modificação posterior, para prever impactos na arquitetura e funcionalidade, durante o processo de desenvolvimento do software (OLIVEIRA, 2003).

No projeto de um website, além da correta adequação dos wireframes, torna-se necessário vislumbrar aspectos que considerem os impactos que as decisões tomadas terão sobre o sucesso do mesmo.

\subsection{A Arquitetura da Informação para a $W e b$}

Levando-se em consideração volume de informação produzido diariamente, e que vem crescendo a cada dia, verifica-se conforme indicado por Reis (2007) que todos os anos, são produzidos aproximadamente 1,5 bilhões de gigabytes, armazenados nos mais variados suportes de informação, o que fornece em média de 250 megabytes de informação para cada ser humano. Estes números evidenciam a crescente demanda informacional dos usuários,

\footnotetext{
${ }^{7}$ Encontrabilidade ou Achabilidade é uma possível tradução do termo "findability"
} 
ressaltando-se também desta forma a importância dos aspectos de usabilidade e acessibilidade dos websites.

Esta demanda informacional tem impulsionado questionamentos sobre a forma que os websites se comunicam com seus usuários, devendo-se considerar o aspecto referente ao acesso à informação mais importante que o simples acesso aos dados, como proposto por Morville e Rosenfeld (2006, p. 74). 0 termo "Arquitetura da Informação" foi criado por Wurman (1991), com o intuito de combater a situação conhecida como "ansiedade da informação", entretanto a Arquitetura da Informação para a web baseia-se no conceito de "ecologia da informação", composto pela combinação de usuários, conteúdo e contexto, de forma a contemplar as dependências complexas que existem (MORVILLE; ROSENFELD, 2006, p. 24). Os usuários correspondem à parte mais importante de qualquer sistema, devendo-se considerar aspectos relativos às suas necessidades, comportamento, grau de experiência; o conteúdo refere-se às informações disponibilizadas no website, a exemplo de documentos, aplicações, serviços, conjunto de metadados utilizados para recuperar informação; e o contexto de uso, refere-se aos objetivos empresariais, onde cada instituição possui sua missão, estratégias, cultura. Reis (2007, p. 63) esclarece que: "No projeto de websites, a Arquitetura de Informação é responsável por definir a estrutura, o esqueleto que organiza as informações sobre o qual todas as demais partes irão se apoiar". Diversas são as definições na literatura para AI na web, entendemos que a área está ainda em evolução, desta forma preferimos não nos acostar a uma única definição do termo.

Para manter a harmonia em website, é necessário que as informações estejam organizadas através de sistemas interdependentes, cada qual com suas regras próprias. Morville e Rosenfeld (2006, p. 43) consideram que a Arquitetura da Informação para a web envolve as formas básicas para disponibilizar informações nos websites por meio dos seus sistemas de organização, navegação, rotulação e busca. O Sistema de Organização (Organization System) realiza o agrupamento e categorização do conteúdo informacional; o Sistema de Navegação (Navigation System) estabelece a maneira de navegar, de movimentar-se pelo espaço informacional e 
hipertextual; o Sistema de Rotulação (Labeling System) determina as formas de representação e apresentação da informação; e o Sistema de Busca (Search System) tem o objetivo de determinar as perguntas que os usuários podem fazer e as respostas que se pode obter para tais questionamentos. De forma a complementar as definições anteriores, o Information Architecture Institute (2002, p. 1), define a AI para Web como "a arte e ciência de organizar e rotular, websites, intranets, comunidades online e software, para suportar usabilidade". A usabilidade deve fazer parte do projeto dos websites desde o início, uma vez que se faz necessário considerar-se à interação com o usuário, aspectos de cognição humana, grau de experiência com a utilização de computadores e sistemas de informação, dentre outros.

A AI para a Web tem ganhado destaque tanto no meio acadêmico quanto empresarial, através dos projetistas de interfaces. Esse sucesso está relacionado com a aplicação dos conceitos envolvidos e recursos que podem tornar os websites mais compreensíveis e agradáveis para os usuários. É possível perceber que normalmente a estrutura encontrada nos websites com princípios de AI apresentam diferenciais, mas que isto, ainda não é suficiente para controlar a qualidade do conteúdo disponibilizado, sendo necessário considerse também questões referentes ao conteúdo e seus respectivos direitos autorais.

\section{A ARQUITETURA DA INFORMAÇÃO NA WEB E OS DIREITOS AUTORAIS}

As maiores transformações na evolução da lei de direitos autorais, tanto de natureza jurídica como econômica decorreram fundamentalmente a partir da invenção da imprensa, por Gutemberg, no ano de 1450. Porém, a primeira manifestação de proteção aos direitos autorais no Brasil, aconteceu em 11 de agosto de 1827, quando foram criados os cursos jurídicos, um na cidade de São Paulo e outro na cidade de Olinda onde eram assegurados aos professores os direitos sobre suas obras (BRANCO JÚNIOR, 2007, p. 19).

Com a aprovação da Constituição Federal de 1988, a proteção autoral teve sua previsão no Capítulo I; Dos Direitos e Deveres Individuais e Coletivos, em seu art. 5o, incisos XXVII e XXVIII, que assegura a participação em obras 
coletivas, descentralização do poder de fiscalizar o aproveitamento econômico da obra intelectual outorgado ao autor e, pela primeira vez, menção ao interprete, reconhecendo-se os direitos conexos.

Os direitos autorais na atualidade são de extrema relevância em qualquer atividade do conhecimento, sendo necessário o conhecimento das normas que os regem. Em especial, a observância à Lei 9.610, de 19 de fevereiro de 1998, que altera, atualiza e consolida a legislação sobre direitos autorais e dá outras providências.

\subsection{A preocupação com os direitos autorais}

A importância da AI transcende considerações técnicas, porém não pode estar alheia a considerações legais. Uma separação de responsabilidades pode deixar obscura a relação entre a AI com seus blocos básicos de construção, e as leis vigentes, que podem influenciar na produção dos respectivos sistemas. Restrições técnicas e legais podem interagir de diferentes formas.

As questões técnicas efetivamente não consideram as leis, onde as restrições impostas pelas mesmas podem impedir ou desencorajar a se ter um determinado comportamento, face ao exercício de alguns direitos e também de deveres (SCHEWICK, 2010, p. 26). 0 desconhecimento, normalmente utilizado como pretexto, não justifica os meios utilizados. Por exemplo, sistemas de controle de acesso, controlam o acesso a certas informações, em que existe a possibilidade de cópia de conteúdo ou a proibição da mesma, fazendo com que o processo de cópia de conteúdo ou de definição de sistemas de forma ilegal não seja realizado, respeitando-se a doutrina de utilização justa da lei de direitos autorais.

A incapacidade para compreender estas ligações pode resultar em políticas ou estratégias que influenciem de forma positiva ou negativa o potencial econômico dos sistemas técnicos. 0 precípuo interesse das instituições em ampliar a abrangência da propriedade intelectual é o de assegurar o aumento de suas respectivas receitas, através da exploração econômica dos produtos culturais sobre seu domínio. Há esse interesse porque principalmente a partir do final do século XX, essas instituições, além de terem 
incorporado um rol de atividades ainda mais complexas, agregam para si a função de gerir e arrecadar os direitos intelectuais de diversos produtos culturais (PEREIRA, 2011, p. 1). Para entender e explorar estas ligações, os arquitetos da informação e demais envolvidos no processo, precisam aprender um pouco sobre as leis que os cercam, enquanto operadores do direito podem auxiliar quanto ao direito de uso da informação.

A utilização eficaz e consciente das leis pode até mesmo vir a apoiar as restrições arquiteturais, criminalizando as tentativas de contorná-las, ou pode enfraquecer a sua eficácia, proibindo a sua utilização. Existe uma necessidade imediata de se ter leis que melhor protejam os direitos das pessoas no ciberespaço, como forma de regulamentar as liberdades civis, com um potencial efeito de proteção aos direitos autorais. Em particular conceitos envolvendo a AI com intuito de incentivar o pensamento sobre os direitos autorais que envolvem o conteúdo dos websites, principalmente para os profissionais responsáveis pela concepção de projetos, como aqueles responsáveis pela inserção/alteração de conteúdo.

\subsection{A aplicação da lei de direito autoral sobre a Arquitetura da Informação}

A informação deve estar disponível para os usuários em todos os momentos, podendo ser compreendido como um questionamento relevante, a existência de uma grande diversidade de websites, que pode contribuir para uma efetiva utilização desta informação, em virtude dos mesmos possuírem e se mostrarem com os mais diversos objetivos. A informação que pode ser entendida como relevante para alguns usuários pode não ser para outros, dependendo de seus interesses, onde a falta ou excesso de informação pode causar uma desorientação independente do projeto do website, sendo imprescindível considerar aspectos de AI, destacando os sistemas de organização, navegação, rotulação e busca.

Nesse sentido, considerando a importância da AI e fazendo uma analogia ao exercício da arquitetura previsto na Lei no 12.378 , de 31 de dezembro de 2010, que regulamenta o exercício da Arquitetura e Urbanismo, cria o Conselho de Arquitetura e Urbanismo do Brasil - CAU/BR e os Conselhos de Arquitetura e 
Urbanismo dos Estados e do Distrito Federal - CAUs; e dá outras providências; o arquiteto tem, de acordo com o art. $2^{\circ}$, II, da referida lei, a atribuição de coleta de dados, estudo, planejamento, projeto e especificação, aplicados aos campos de atuação previstos no parágrafo único do mesmo artigo. Segundo o art. 3ㅜㅜ encontram-se dispostos aspectos relativos a formação do profissional arquiteto e urbanista nas quais os núcleos de conhecimentos de fundamentação e de conhecimentos profissionais caracterizam a unidade de atuação profissional.

Assim, verifica-se que da mesma forma que um arquiteto faz uma planta baixa de uma casa, o profissional da $\mathrm{AI}$ ao definir a estrutura navegacional do website, organizando hierarquicamente os elementos e informações que devam estar presentes em cada uma das páginas do sistema, ele está construindo um wireframe, de forma similar a um projeto correspondente a uma planta baixa. No entanto, não há, pelo menos até o momento, no sistema jurídico brasileiro uma lei que venha a regulamentar a atividade do arquiteto da informação para construção dos wireframes ou de forma mais genérica da definição e disposição dos elementos de um website ou de qualquer outra estrutura informacional. 0 que se constata é a questão de que não há uma atividade regulamentada para que possa haver registro do profissional habilitado para tal atividade.

Isso decorre, ao contrário do que existe com o exercício da arquitetura e urbanismo, em que todas as atividades desenvolvidas pelos profissionais desta área, estão descriminadas nos arts. 2ำ e 3o da lei específica. Na AI para a Web, na construção de wireframes, por não haver atividade regulamentada em lei específica, torna-se difícil à aplicação do direito autoral no que lhe diz respeito.

Embora haja na visão do usuário uma abstração das páginas construídas, bem como no pensamento de Winton Churchill, descrito por Morville (2005, p. 42), de que "moldamos nossos edifícios; depois eles nos moldam", a representação do que construímos pode ser visualizada com um novo sentido. Nesse pensamento, como o wireframe fica exposto para ser copiado por outras pessoas, pode-se mudar apenas o sentido da aplicação, podendo apropriar-se indevidamente da propriedade intelectual de outrem.

0 que se torna visivelmente necessário à regulamentação deste aspecto para que a lei de direito autoral também possa cumprir seu papel na defesa 
do(s) profissional(ais) envolvido(s) no projeto, uma vez que a Lei no 9.610, de 19 de fevereiro de 1998, correspondente a Lei dos Direitos Autorais (LDA) vem a consolidar a legislação sobre o referido assunto.

Segundo Menezes (2007, p. 19), o direito do autor busca resguardar a subjetividade do vínculo do autor com sua obra possibilitando fruto econômico derivado de sua exploração comercial. Porém, existem outras visões, como no caso do pensamento de Bittar (2003), em que é o ramo do direito privado que regula as relações jurídicas advindas da criação e utilização econômica de obras intelectuais. Trata-se de um conjunto de privilégios de natureza pessoal e patrimonial cuja aquisição originária está diretamente vinculada ao exercício da atividade artística, científica ou literária. Em outras palavras, é o conjunto de direitos resultantes das concepções da inteligência materializadas sob a forma de arte e cultura.

No texto da lei de direitos autorais, em seu art. 7ํ, caput, esclarece que são consideradas protegidas as criações do espírito expressas por qualquer meio ou fixadas em qualquer suporte, tangível ou intangível, conhecido ou que se invente no futuro. Verifica-se que para que haja a devida proteção, torna-se necessário como requisito, que se trate de criações do espírito, especificada nos incisos enumerados no artigo 7ํ․ Entre os referidos incisos, estão citados os produtos de software; que no $§ 1^{\circ}$ - deixa explicito que são objetos de legislação específica, observadas as disposições desta Lei que lhes sejam aplicáveis. Isto implica que se comparando a Lei de Direitos Autorais, com a Lei no 9.609/98, que dispõe sobre a proteção da propriedade intelectual de programa de computador, e sua comercialização no país, é possível chegar ao entendimento de que seus dispositivos servem, no entanto, de exceção a LDA.

No entendimento de Paranaguá (2009), isso significa que a LDA se aplica também, em sua totalidade, aos produtos de software, exceto naquilo que a Lei no 9.609/98 dispuser em contrário, trazendo de inovação questões sobre pontos que devem ser levados em consideração, como o direito do autor de reivindicar a paternidade do programa e de se opor a alterações não autorizadas, quando estas impliquem deformação, mutilação ou outra modificação que prejudique a sua honra ou reputação (art. $2^{\circ}$, $\S^{1} \stackrel{\circ}{ }$ ); a proteção 
dos referidos produtos de software pelo prazo de 50 anos, contados a partir de

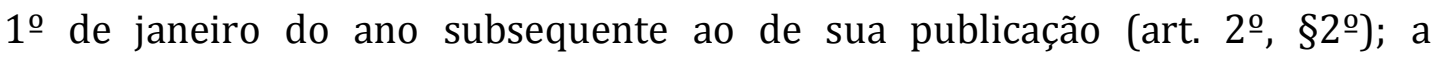
autorização de uma única cópia do programa, ao afirmar que não constitui ofensa aos direitos do titular do programa a reprodução, em um só exemplar, de cópia legitimamente adquirida, desde que se destine à cópia de salvaguarda ou armazenamento eletrônico (backup) (art. 6o, I); e quanto à circulação econômica do referido programa, determina que esta deva ser objeto de contrato de licença. No entanto, na hipótese de eventual inexistência do contrato de licença, o documento fiscal relativo à aquisição ou ao licenciamento de cópia serve de comprovação da regularidade de seu uso.

No sentido de que o programa de computador embora se trate de criação de direito de autor, deve ser regido por lei própria, no caso, a Lei no 9.609/98, onde é possível verificar notável problema à aplicação do direito ao que se refere à segurança das aplicações do direito nos tribunais. Pois, é possível conferir a existência de lacunas sobre especificações e termos técnicos dos diversos tipos de produtos de software na lei, suscitando margem de insegurança, ficando a critério dos operadores do direito interpretações que podem ser criadas de forma equivocada. Neste sentido, pode-se perceber que através de uma perícia realizada por técnico especializado sobre os produtos de software é possível que este aponte que pelo menos três aspectos são claramente visíveis na avaliação do que se tenta proteger através do direito autoral e que não são referidos na lei. Destacam-se os "códigos-fonte" dos sistemas de informação; a estrutura dinâmica de uso e o projeto (design) existente no software (este não pertencente ao software, mas ao conteúdo nele exposto).

Os “códigos-fonte" (estrutura de programação) são os caminhos trilhados pelo programador para alcançar uma finalidade, sendo a referida estrutura considerada uma criação autoral, pois se trata de uma criação do espírito. Neste sentido, a forma pela qual se alcança a finalidade é que deve ser considerada criação autoral, uma vez que a finalidade em si não pode ser considerada como propriedade pelo programador. Quanto ao projeto ou aparência gráfico-estética exposta, a disposição de imagens, de desenhos e do conjunto ou esquema global 
de figuras e cores compõem a criação do espírito humano, são aptas a serem protegidos pelo direito de autor embora pareçam inadequadas. Desta forma, sob a modalidade de wireframes, o projeto será protegido não somente pela lei 9.609/98 que dispõe sobre a proteção da propriedade intelectual de programa de computador, mas também pela lei de proteção dos direitos de autor (Lei 9.610/98). Os desenvolvedores podem utilizar templates ${ }^{8}$ de sistemas, principalmente para a construção de páginas Web, mas respeitando o tipo de licença estabelecido. Na prática, existem diversos mecanismos e projetos de licenças públicas e criações colaborativas, com intuito de combater plágio, o que tem como principal efeito o aumento do domínio público e, consequentemente, a possibilidade de uso de ideias alheias, independentemente de autorização expressa dos titulares de seus direitos autorais, mas sem o risco de processos judiciais.

A licença é uma autorização dada pelo autor para que um terceiro se valha da obra, com exclusividade ou não, nos termos da autorização. É considerável a quantidade de tipos de licenças existentes, onde é possível especificar os direitos do usuário, sendo o software considerado como proprietário, livre, dentre outros, mas sem destaque na lei para partes específicas, como o que pode estar definido nos wireframes. Ao utilizar as licenças, do ponto de vista jurídico, mesmo com software livre o autor não está abrindo mãos dos direitos autorais, mas, fazendo uso de seu direito de autor, para que com uma licença adequada possa condicionar esses direitos a terceiros. Nesse sentido, a proteção aos wireframes, ou projetos arquitetônicos dos websites, não são pensados especificamente, e consequentemente não regulamentos pela lei ou licença correspondente. 0 que se pode perceber é que os mesmos ficam implícitos, mas com possibilidade de múltiplas interpretações, podendo gerar controvérsias nos tribunais.

Algumas alternativas podem ser vislumbradas, a exemplo do respeito à autoria das obras, independentemente se está na forma impressa (papel) ou na

\footnotetext{
${ }^{8}$ Os templates correspondem a modelos que servem de matriz para a produção em escala de um produto.
} 
forma de bits e bytes (em DVD, BLURAY, páginas web, etc.). Porém vários questionamentos podem surgir, a exemplo da forma como proceder para se ter acesso as diferentes fontes de informação, e como essas fontes estarão disponíveis no futuro para novos tipos de mídias.

\section{CONSIDERAÇÕES FINAIS}

No mundo globalizado, o acesso à informação tem se tornado essencial para que os usuários possam exercer cidadania. 0 combate à cópia de forma indevida não é uma tarefa que apresenta simplicidade, necessitando-se de políticas públicas de acesso à informação, que se bem definidas, podem evitar problemas sociais, seja da cópia indevida de conteúdos e ideias, seja da exclusão de acesso à informação.

Neste artigo, procurou-se articular conceitos envolvendo a AI com outros próprios relativos aos direitos autorais. A discussão apresentada tem o intuito de incentivar o pensamento sobre os direitos autorais que envolvem a AI associada aos websites, principalmente para os profissionais responsáveis pela concepção de projetos, como aqueles responsáveis pela inserção/alteração de conteúdo. As estratégias para produção e organização das informações, para aumentar as chances de sucesso, devem contemplar tanto os princípios recomendados pela $\mathrm{AI}$, quanto às considerações sobre a necessidade de se respeitar os direitos dos autores das obras, não efetuando cópias sem citação da referida autoria, ou apropriando-se indevidamente de estruturas (wireframes) pensadas por outrem. A análise pode ser realizada tanto quanto a organização da informação, quanto no conteúdo mostrado. A organização da informação pode facilitar o entendimento das informações por parte do usuário, e o conteúdo pode contemplar novas informações ou cópias de outras já existentes, mas para evitar problemas com a justiça no que tange aos aspectos de direitos autorais das obras publicadas, os profissionais envolvidos devem considerar as leis existentes.

Conhecer o que existe nos vários ambientes informacionais, preservando-se os direitos dos autores, podem ser iniciativas que possibilitem a 
geração de informações de forma adequada, com objetivo de estabelecer horizontes que contemplem o respeito, oriundo da interação entre os usuários.

A aplicação das leis, não deve ser considerada puramente coercitiva, mas como uma regra que deve ser seguida por todos, e que implicitamente represente uma forma ética de trabalhar no mundo globalizado, respeitando-se o poder de criação e realizando inovação, onde a criatividade pode ser usada para alcançar o sucesso no mundo virtual. A concepção de leis específicas ainda é um fator que precisa ser discutido, mas que sua identificação já abre horizontes que outrora poderia ser considerado como impraticáveis ou impossíveis de serem adotas no ciberespaço.

A Internet pode influenciar na forma de se obter resultados satisfatórios, dependendo das políticas adotadas, podendo o usuário passar de um posicionamento passivo (apenas de leitor de informações) para uma posição proativa, onde as tecnologias utilizadas passem a disseminar ideias, sendo ético, criando e recriando novos saberes.

A partir da conceituação apresentada neste artigo, verifica-se a possibilidade de refletir para a construção de seu objeto que tem como temática mater Arquitetura da Informação na web: Reflexões Relativas à Lei dos Direitos Autorais, uma vez que o tema limita-se a apenas um recorte dentro das várias fases do desenvolvimento de um sistema de informação. Neste sentido, justifica-se a importância deste estudo no sentido de que viabiliza reflexões teóricas em torno do campo ainda em investigação. Algumas alternativas possíveis para solução quanto à proteção dos wireframes, referemse a ajustes nas leis existentes, ou criação de lei específica para tal propósito, com o objetivo de minimizar as lacunas existentes, além do claro estabelecimento do que pode ser protegido quanto à arquitetura dos referidos sistemas. 


\section{REFERÊNCIAS}

BITTAR, Carlos Alberto. Direito de Autor. 4. ed. São Paulo: Forense universitária, 2003.

BRANCO JÚNIOR, Sérgio Vieira. Direitos Autorais na Internet e o uso de Obras Alheias. Rio de Janeiro: Editora Lumen Juris, 2007. Disponível em:

<http://virtualbib.fgv.br/dspace/bitstream/handle/10438/2832/Sergio\%20Br anco\%20-\%20Direitos\%20Autorais\%20na\%20Internet.pdf?sequence=1>. Acesso em: 07 dez. 2010.

BRASIL, Constituição (1988). Constituição da República Federativa do Brasil. Brasília, DF: Senado Federal: Centro Gráfico, 1988.

BRASIL. Lei 9.609, de 19 de fevereiro de 1998. Dispõe sobre a proteção da propriedade intelectual de programa de computador, sua comercialização no País e dá outras providências. Diário Oficial [da República Federativa do Brasil], Brasil, 20 fev. 1998.

BRASIL. Lei 9.610, de 19 de fevereiro de 1998. Altera, atualiza e consolida a legislação sobre direitos autorais e dá outras providências. Diário Oficial [da República Federativa do Brasil], Brasil, 20 fev. 1998.

BRASIL. Lei 12.378, de 31 de dezembro de 2010. Regulamenta o exercício da Arquitetura e Urbanismo; cria o Conselho de Arquitetura e Urbanismo do Brasil - CAU/BR e os Conselhos de Arquitetura e Urbanismo dos Estados e do Distrito Federal - CAUs; e dá outras providências. Diário Oficial [da República Federativa do Brasil], Brasil, 31 dez. 2010 - Edição Extra.

CAPOBIANCO, Ligia. A Revolução em Curso: Internet, Sociedade da Informação e Cibercultura. São Paulo: Universidade de São Paulo, 2010. Disponível em <http://www.ec.ubi.pt/ec/07/vol2/capobianco.pdf>. Acesso em: 02 dez. 2010. CASTELLS, Manuel. A sociedade em rede. São Paulo: Paz e Terra, 1999. MENEZES, Elisângela Dias. Curso de Direito Autoral. Belo Horizonte: Del Rey, 2007.

BUSTAMANTE, A. M. O. S. Arquitectura de información y usabilidad: nociones básicas para los profesionales de la información. ACIMED, Havana, v. 12, n. 6, 2004. Disponível em: 
<http://scielo.sld.cu/scielo.php?script=sci_arttext\&pid= S1024-

94352004000600004\&lng=es\&nrm=iso >. Acesso em: 21 mar. 2011.

MORVILLE, Peter. Ambient Findability: What We Find Changes Who We Become.

Sebastopol: O'Reilly, 2005.

MORVILLE, Peter; ROSENFELD, Louis. Information Architecture for the World Wide Web. 3. ed. Sebastopol: O'Reilly, 2006.

OLIVEIRA, Leonardo. Wireframe: documento cada vez mais importante.

Webinsider, 2003. Disponível em:

<http://webinsider.uol.com.br/2003/12/09/wireframe-documento-cada-vezmais-importante>. Acesso em: 02 dez. 2010.

PARANAGUÁ, Pedro; BRANCO, Sérgio. Direitos autorais. Rio de Janeiro: Editora FGV, 2009. Disponível em:

<http://virtualbib.fgv.br/dspace/bitstream/handle/10438/2756/

Direitos\%20autorais_net.pdf?sequence=1>. Acesso em: 02 dez. 2010

PEREIRA, Márcio Ferreira Rodrigues. Direito de autor ou de empresário?

Indústrias culturais e direito autoral na contemporaneidade. Jus Navigandi,

Teresina, v. 16, n. 2757, jan. 2011. Disponível em:

<http://jus.uol.com.br/revista/texto/18293>. Acesso em: 21 fev. 2011.

PRESSMAN, Roger S. Engenharia de Software. 6. ed. São Paulo: McGraw-Hill, 2006.

REIS, Guilhermo Almeida dos. Centrando a Arquitetura de Informação no usuário. São Paulo, 2007. Dissertação (Mestrado) - Escola de Comunicação e Artes, Universidade de São Paulo. Disponível em:

<http://www.guilhermo.com/mestrado/Guilhermo_Reis-

Centrando_a_Arquitetura_de_Informacao_no_usuario.pdf>. Acesso em: $06 \mathrm{dez}$. 2010.

SCHEWICK, Barbara van. Internet Architecture and Innovation. Cambridge: The MIT Press, 2010.

SILVA, Sandra Maria Glória da. Utilização das Tecnologias de Informação e Comunicação como Recurso Educativo na Formação Profissional. SENEPT Seminário Nacional de Educação Profissional e Tecnológica. CEFET-MG, 2010. Disponível em: 
<http://www.senept.cefetmg.br/galerias/Anais_2010/Artigos/GT2/UTILIZACA O_DAS_TECNOLOGIAS.pdf>. Acesso em: 21 mar. 2011.

SOUSA, Marckson Roberto Ferreira et al. InfoArch: uma ontologia para modelar o domínio da Arquitetura da Informação para Web. XI Encontro Nacional de Pesquisa em Ciência da Informação - XI ENANCIB, Rio de Janeiro, 2010. THE INFORMATION ARCHITECTURE INSTITUTE. What is Information Architecture?, 2002. Disponível em:

<http://iainstitute.org/documents/learn/What_is_IA.pdf>. Acesso em: $07 \mathrm{dez}$. 2010.

WURMAN, Richard Saul. Ansiedade de Informação. São Paulo, SP: Cultura Editores Associados, 1991. 